\title{
PRELIMINARY INVESTIGATION
}

\section{ON FISH SPECIES ASSOCIATED}

\section{WITH CIGUATERA POISONING IN}

\section{SOUTHERN COASTAL AREAS IN}

\section{SRI LANKA}

\author{
By \\ Kankanamge Hiranthi Samanthika Walpola \\ (MSc./Ls/0018)
}

MSc.

2005 


\title{
PRELIMINARY INVESTIGATION ON FISH SPECIES
}

ASSOCIATED WITH CIGUATERA POISONING IN

SOUTHERN COASTAL AREAS IN SRI LANKA

\section{By}

Kankanamge Hiranthi Samanthika Walpola

\author{
(MSc./LS/0018)
}

Thesis submitted to the University of Sri Jayewardenepura for the award of the Degree of Master of Science in Fisheries and Aquatic Resources Development

January 2005 
"The work described in this thesis was carried out by me under the supervision of Miss. Geewika Ganegamaarachchi and a report on this has not been submitted in whole or in part to any university for another

\section{Degree"}

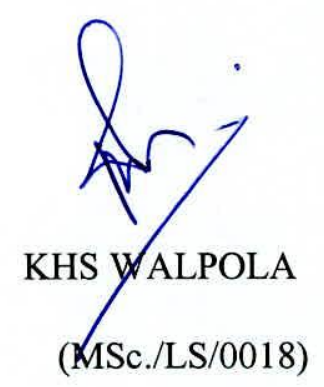

"I/We certify that the above statement made by the candidate is true and that this

thesis is suitable for submission to the university for the purpose of evaluation"

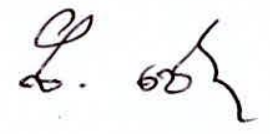

Miss G Ganegamaarachchi

National Aquatic Research and Development Agency

Colombo 15

Sri Lanka 


\section{CONTENTS}

LIST OF FIGURES

LIST OF TABLES

II

ACKNOWLEDGEMENT

III

ABSTRACT

IV

\section{CHAPTER 1 INTRODUCTION}

1.1 - Background 1

1.2 - Chemistry of Ciguatoxin 3

1.3 - Mode of action 3

1.4 - Clinical symptoms of Ciguatera fish poisoning 4

1.5 - Pathaphysiology of Ciguatoxin 5

1.6 - Identification of Fish species 6

$1.7 \quad$ - Identification of fish parts that cause CFP $\quad 7$

1.8 - Ciguatera fish poisoning in Sri Lanka $\quad 8$

1.9 - Objectives of this project $\quad 8$

\section{CHAPTER O2 METHODOLOGY}

$\begin{array}{lll}2.1 & \text { study area } & 10\end{array}$

$\begin{array}{ll}2.2 & \text { Target groups and data collection }\end{array}$ 


\section{CHAPTER 03 RESULTS}

3.1 Reported ciguatera symptoms from nonfishing community 12

3.2 Reported ciguatera symptoms from fishing community

3.3 Reported cases of ciguatera symptoms at hospital/private medical practitioners.

3.4 Summarizes the total number of people with reported ciguatera systems within last 10 years.

3.5 Rate of ciguatera poisoning in southern coastal area in srilanka within the last 10 years time

3.6 Identified fish species that ciguatera poisoning 16

3.7 Identified fish parts that cause ciguatera fish poisoning in sri lanka

3.8 Cigua check R Test for identification of ciguatera poison fish 18

3.9 Preparation of a leaflet to create awarencess on ciguatera fish poisoning. 


\section{LIST OF FIGURES}

FIGER 01 - Study areas in southern coastal areas in sri lanka

FIGER 02 -. Leaflet produced to create awareness on ciguatera fish poisoning 18

\section{LIST OF TABLES}

Table - 3.1 - Tatal of people with reported ciguatera symptoms from nonfishing community (Within 10 years time)

Table -3.2 - Tatal of people with reported ciguatera symptoms from fishing community (Within 10 years time)

Table -3.3 - Tatal of people with Reported ciguatera symptoms brought to hospital/private medical practitioners in the study area (Within 10 years time)

Table -3.4 - Tatal amount of patients reported ciguatera symptoms (Within 10 years time) 


\section{ACKNOWLEDGEMENTS}

I wish to express my deepest gratitude for the continuous guidance, advice and encouragement given to me by my supervisor Miss Geewika Ganegamaarachchi, Research Officer, Post harvest Technology Division, National Aquatic Resources Research and Development Agency (NARA).

My sincere gratitude also goes out to Dr.(Mrs) Ajantha de Alwis, Senior Lecturer, Department of Zoology ,University of Sri Jayewardenepura , for poviding me with this great opportunity and providing the facilities for the project.

I must very kindly thank all the people who live in the research sites for giving me a great support to do this project successfully.

I gratefully acknowledge the support given by Mr. Yasas Palinda in the field work . Special thanks to my friend Shyama for helping me in statistical analysis . I also like to thank Sriyani and Malkanthi for supporting me in the preparation of the leaflet sacrificing their valuable time for me .

Finally I would like to express my special thanks to all of my colleagues who helped me to do this project successfully. 


\begin{abstract}
Ciguatera fish poisoning is the most common nonbacterial fish borne poisoning in most of the countries in the world. It is caused by consumption of fish that feed on certain dinoflagellates. It is a serious economical and public health problem worldwide, wherever reef fish are caught and consumed. As many coral reef associated fish species are very common as food fish among Sri Lankans, it is very important to know about of Ciguatera fish poisoning in the country ; the fish species causing this condition; the body parts of fish responsible in causing poisoning and the agents which make the fish poisonous.
\end{abstract}

In the present study, southern province of Sri Lanka was selected as the study area, as many coral associated fish are consumed in this area. Randomly selected 32 sites were surveyed from $01 / 06 / 2004$ to $31 / 12 / 2005$ over period of six months, by a quantitative methodology with the use of a questionaire method for collecting quantitative primary data. Fish identification sheets were also used to identify suspect fish species. The target groups of this survey included, Fishing community (including those who are currently involved in fishing industry as well as older fishermen retired from fishing industry), fish consumers or retailers in the study area (non fishing community) and medical practitioners (both government and non government) in the area.

50 families were interviewed from each of non fishing communities at each site. 32 medical practitioners both government and non government organizatitions close to each site were consulted to get information. 
Results indicate that, only one child was reported to have suffered from 1600 non fishing families and 1600 fishing families investigated.

Using above surveyed data, annual ciguatera poisoning rate in southern coastal areas in Sri Lanka was calculated as $0.0001 \%$. Some species of snappers and groupers were the observed ciguatoxic fish species.

These results suggest that Ciguatera fish poisoning is not occurring at a dangerous level at present. But with the increasing consumption of coral reef fish species in the country more attention should be given towards this. A proper data base on Ciguatera poisoning in the country should be maintained and regular checking for the poison species have to be caried out. Awareness programme on this subject is also stressed. There should be a programme to train relevant personnel in identification 


\subsection{INTRODUCTION}

\subsection{Background}

Consumer perceptions of sea foods include the benefits of high quality protein, n-3 fatty acids and minerals accompanied by low fat and low calories. They are also aware, usually due to overemphasis by the media, of spoilage, rancidity, effects of pollution, allergies, and sea food borne illness. Such hazards originate in the environment through both naturally occurring microorganisms and toxins, and from contamination by viruses and chemicals(Tucker, 1995).

Ciguatera fish poisoning was described as early as 1606 in the South Pacific island chain called New Hebrides. A similar outbreak there and in nearby New Caledonia was reported in 1774 by the famed English navigator, Captain James Cook. He described the clinical symptoms of his sick crew, symptoms that coincide with those described today.

In addition, viscera from the same fishes eaten by Cook's crew were given to pigs, causing their death (Anon,2004a).

The term Ciguatera originated in the Caribbean area to designate intoxication induced by the ingestion of the marine snail Turbo pica(called cigua), described by a Cuban ichthyologist. Today, the term is widely accepted to denote a particular type of fish poisoning which results from ingestion of certain fishes (primarily reef fishes) 
encountered around the islands in the Caribbean and the Pacific. Current information points to one of the many polyether toxins, such as ciguatoxin and related compounds, which are structurally similar to okadaic acid. (Anon,2004a).

Since the late 1970 's, several scientists have made much progress in all areas of ciguatera research. These areas include; biology, chemistry (including the closely related polyethers), pharmacology, clinical information and immunological analysis or the testing or detection of the major toxin, ciguatoxin, and its related polyether toxins (Anon,2004a).

Ciguatera fish poisoning is reported to be the most common nonbacterial, fish borne poisoning. It is caused by consumption of fish that feed on certain dinoflagellates (ie.algae) associated with coral reef systems. At least 5 types of ciguatoxins have been identified and are noted to accumulate in larger and older fish higher up in the food chain. Ciguatera fish poisoning has been a significant concern in tropical areas for centuries and generally is believed to be confined to coral reef fish in waters between the latitudes of $35 \mathrm{~N}$ and $35 \mathrm{~S}$. This includes the tropical and subtropical shorelines where as many as 400 million people live. It is reported that more than 60000 people get Ciguatera poisoning each year worldwide. due to the fact that rapid transportation in the modern era has facilitated the availability of tropical and subtropical fish species all over the world (Anon,2004b). 


\subsection{Chemistry of Ciguatoxins}

These ciguatoxins are heat stable, lipid soluble cyclic polyethers.. More than 20 types of ciguatoxins are known and vary with geographical origin and fish species(Anon,2004c)

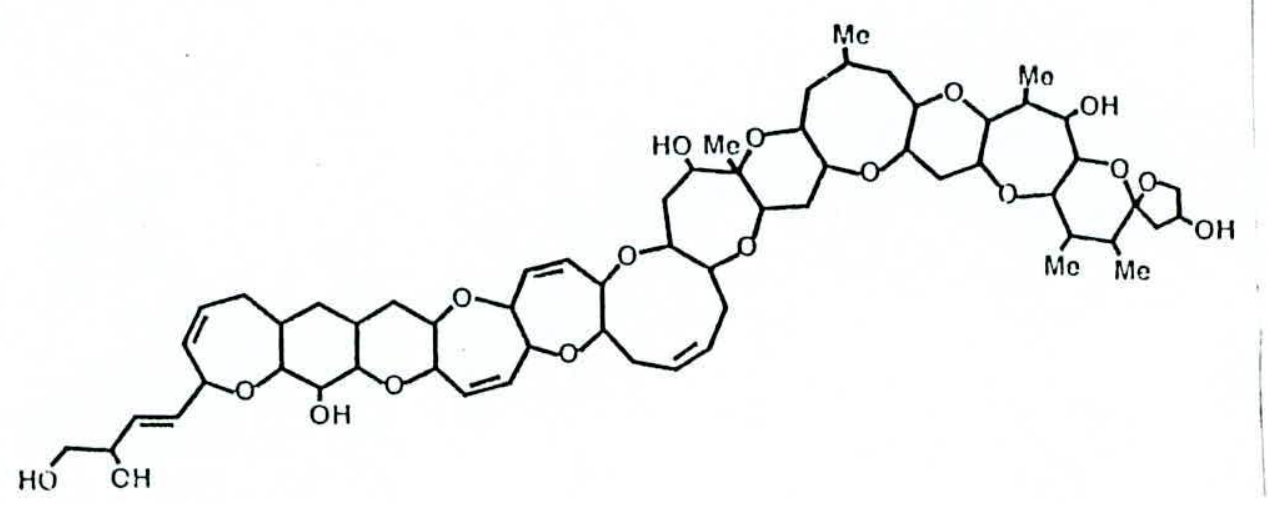

Basic structure of Ciguatoxins

\subsection{Mode of action}

Cigua toxins are the most potent sodium channel toxins known. They activate voltage sensetive sodium channels. (Anon,2004c)

Ciguatoxin produces toxic effects by activation of voltage-dependent sodium channels, resulting in hyperexcitability, decreased conduction, and prolonged refractoriness. Effects are most pronounced on neuronal, cardiac, and GI tissues(Anon,2004a). 


\subsection{Clinical symptoms of ciguatera fish poisoning}

Currently, Ciguatera poisoning is a clinical diagnosis based upon a constellation of symptoms temporally related to ingestion of suspect fish products. Onset of symptoms may be within 15 minutes or as 6-12 hours after ingestion of tropical reef fish or even 36 hours after eating a poisonous fish (Anon,2004a).

The clinical symptoms of ciguatera poisoning can be classified into four broad groups: neurologic, cardiovascular, gastrointestinal and general symptoms. The disease commonly begins with the following symptoms:

nausea

vomiting

diarrhoea

generalized weakness

a decreased sensation to pain or touch

unusual or painful sensations produced by ordinary stimuli

a burning or tingling of the hands and legs or around the mouth

muscle pain

temperature reversal sensation(hot things feel cold and vice versa) (Anon,2004c) 
Other less common symptoms include:

* chills

* itching

* dizziness

* sweating

* headache

taste disturbances(a metalic taste or fuzzy sensation)(Anon,2004b)

The nausia, vomiting, and other gastrointestinal symptoms last for approximately 1 to 2 days. Weakness may last for 1 to 7 days. Neurologic symptoms such as tingling or temperature reversal generally persist for up to a week, but it is not unusual for these symptoms to periodically re-occur for a month or more(Anon,2004c).

The only cardiovascular symptom that may be noted by someone who is poisoned is either an increased or decreased heart rate. Others such as low blood pressure, dilated pupils, irregular heart rhythm and diminished or increased reflexes may be noted by a physician. These symptoms resolve in 2 to 3 days. (Anon,2004c)

\subsection{Pathophysiology of Ciguatera fish poisoning}

Gambierdiscus toxicus is the dinoflagellate most notably responsible for production of ciguatoxin, although other species have been identified more recently. Over 400 species of fish have been implicated in 
Ciguatera poisoning, starting with herbivores and then climbing up the food chain to the larger carnivorous fish(Anon,2004a).

Fish larger than $2 \mathrm{~kg}$ contain significant amounts of toxin and readily produce toxic effects when ingested. Although not completely reliable, an immunoassay and mouse biological assay are available for detection of ciguatoxin in affected fish. Ciguatoxin and other similar toxins are heat stable and lipid soluble; they are unaffected by temperature, gastric acid, or cooking method. Presence of toxin does not affect odor, color, or taste of the fish. (Anon,2004a).

\subsection{Some identified fish species that cause Ciguatera fish}

\section{poisoning in the World.}

Following species have been identified as potential Ciguatera fish poisoning.

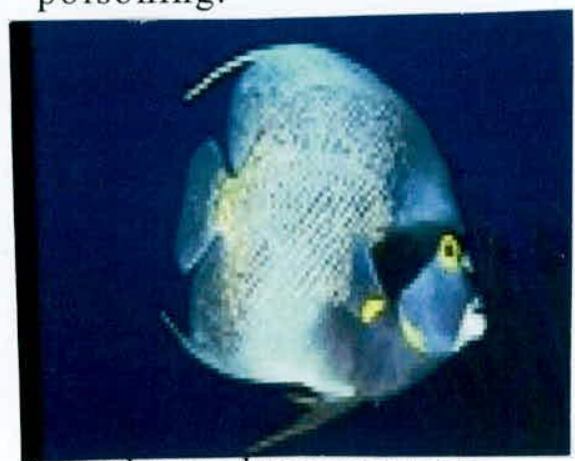

Acanthurus leucosternon

(Family Acanthuridae)

English name : Powder blue surgeon fish

Local name :Nil detha

Tamil name :Nila orandeya

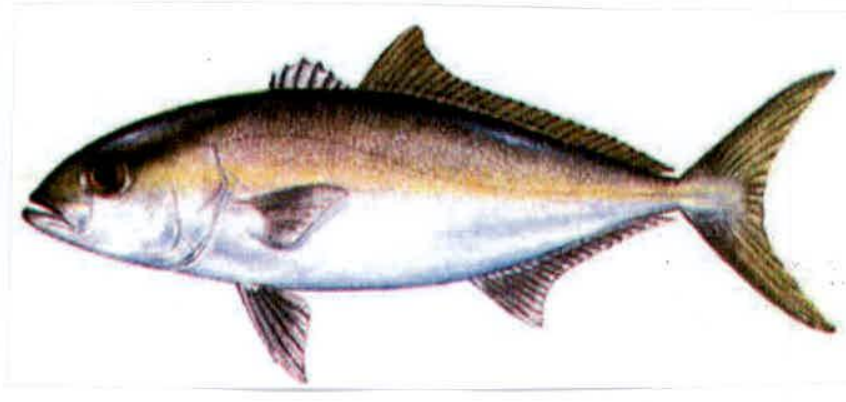

Coranx sexfasciatus

(Family Carangidae)

English name : travelly.

Local name :Inguru parawa

Tamil name :pareh 